\title{
Experimental observations of a nuclear matrix
}

\author{
Jeffrey A. Nickerson \\ Department of Cell Biology and Cancer Center, University of Massachusetts Medical School, 55 Lake Avenue North, Worcester, MA 01655, USA \\ (jeffrey.nickerson@umassmed.edu) \\ Journal of Cell Science 114, 463-474 (C) The Company of Biologists Ltd
}

\section{Summary}

Nuclei are intricately structured, and nuclear metabolism has an elaborate spatial organization. The architecture of the nucleus includes two overlapping and nucleic-acidcontaining structures - chromatin and a nuclear matrix. The nuclear matrix is observed by microscopy in live, fixed and extracted cells. Its ultrastructure and composition show it to be, in large part, the ribonucleoprotein (RNP) network first seen in unfractionated cells more than 30 years ago. At that time, the discovery of this RNP structure explained surprising observations that RNA, packaged in proteins, is attached to an intranuclear, non-chromatin structure. Periodic and specific attachments of chromatin fibers to the nuclear matrix create the chromatin loop domains that can be directly observed by microscopy or inferred from biochemical experiments. The ultrastructure of the nuclear matrix is well characterized and consists of a nuclear lamina and an internal nuclear network of subassemblies linked together by highly structured fibers. These complex fibers are built on an underlying scaffolding of branched $10-\mathrm{nm}$ filaments that connect to the nuclear lamina. The structural proteins of the nuclear lamina have been well characterized, but the structural biochemistry of the internal nuclear matrix has received less attention. Many internal matrix proteins have been identified, but far less is known about how these proteins assemble to make the fibers, filaments and other assemblies of the internal nuclear matrix. Correcting this imbalance will require the combined application of biochemistry and electron microscopy. The central problem in trying to define nuclear matrix structure is to identify the proteins that assemble into the $10-\mathrm{nm}$ filaments upon which the interior architecture of the nucleus is constructed. Only by achieving a biochemical characterization of the nuclear matrix will we advance beyond simple microscopic observations of structure to a better understanding of nuclear matrix function, regulation and post-mitotic assembly.

Key words: Nuclear matrix, RNP network, Nuclear structure, Chromatin organization, Nuclear dynamics

\section{Introduction}

The study of the nuclear matrix has traveled a long and sometimes difficult road to its current position of general acceptance. The journey has been vigorous, as evidenced by a recent MedLine search that recovered 2158 papers for the term nuclear matrix and many more for synonyms such as nuclear scaffold (423) or nucleoskeleton (68). Despite this voluminous literature and some years of acceptance the field has recently come under attack (Pederson, 2000). This criticism is not of specific experimental results but of their interpretation. It posits a nucleus in which free diffusion rules and which, therefore, requires no non-chromatin structure. This concept, however, is at odds with the direct observation of the nuclear matrix in living cells, fixed cells and isolated structures. The nuclear matrix is not a concept; it is a readily observed cellular structure.

Our challenge is to clarify the molecular architecture of this non-chromatin nuclear structure. We know a great deal about nuclear matrix ultrastructure, but we have not sufficiently correlated that information with a biochemical characterization of major structural molecules. Remaining to be specified are the subsets of nuclear matrix proteins forming the filaments and other sub-assemblies clearly observed by electron microscopy. The emphasis in biochemical studies has instead been on the function of the nuclear matrix - for example, in DNA replication or transcription. These studies have been very productive but have not been accompanied by equal efforts to characterize the structural molecules of the matrix and their mechanisms of assembly. These priorities may have been imposed by funding considerations. Nevertheless, they must change.

A similar absence of biochemical characterization fueled criticism of cytoskeletal research a generation ago. The isolation and characterization of tubulin, intermediate filament proteins, non-muscle actins and myosins, followed by the study of their in vitro assembly, removed any sneer directed at the cytoskeleton as a legitimate object of study. What the nuclear structure field has lacked is, metaphorically speaking, a tubulin in the nuclear interior - a major non-chromatin structural protein that has a well-characterized role in intranuclear organization.

\section{What is the nuclear matrix?}

The nuclear matrix has sometimes been defined in unfortunate ways and these, especially 'operational' definitions that refer to specific extraction protocols, have only served to fuel controversy. The appropriate definition is the first. In 1966 Don Fawcett defined the nuclear matrix as the non-chromatin structures of the nucleus readily observed in unextracted cells under the electron microscope (Fawcett, 1966). The principal feature of these non-chromatin nuclear structures is the fibrogranular ribonucleoprotein (RNP) network first identified in the early 1960s (Smetana et al., 1963). The relationship between this RNP structure and the nuclear matrix has been 
obvious for many years. It is an important connection to remember, because it suggests functions and properties that should drive our research efforts.

\section{Experimental foundations of nuclear matrix research}

The field of nuclear matrix research has historically rested on four pillars: (1) the observation by electron microscopy of fibrogranular non-chromatin structures in the nuclei of cultured cells and tissues; (2) the development of protocols for isolating these non-chromatin structures that preserve their ultrastructure; (3) the observation that chromatin is organized in loop domains attached at their bases to a non-chromatin structure; and (4) the discovery of spatially distinct functional domains in the nucleus that remain in place after the removal of soluble proteins and chromatin.

\section{Electron microscopic examinations of nuclear ultrastructure}

Early light microscopy revealed only a few visible structures in the nucleus. The rest of the nucleus looked empty, and this suggested that the sparse structures of the nucleus are suspended in a liquid medium called the nuclear sap or karyolymph (Berezney, 1984; Fawcett, 1966). The advent of electron microscopy changed everything. The vastly superior resolution, sectioning ability and staining contrast revealed a much more highly structured nucleus, in which many substructures contained little DNA. These new observations, argued Don Fawcett (Fawcett, 1966), made terms such as nuclear sap inappropriate, and he suggested nuclear matrix as an alternative to label the non-chromatin structures.

By 1963, Smetna et al. had observed that RNA, packaged in proteins, is part of a continuous nuclear network and that this structure is the source of the RNP particles released from the nucleus by chemical or mechanical extraction (Smetana et al., 1963). These results posed an important question. Is the nuclear RNP network an interconnected structure or is its appearance an artifact caused by the fixation of unconnected fibers and granules that are merely clustered in vivo.

The clear answer is that hnRNA, packaged as RNP, is part of a structure. Removal of the nuclear envelope or even gentle homogenization of the nucleus does not release RNA or RNP particles (Herman et al., 1978); this requires digestion with ribonucleases (Herman et al., 1978; Narayan et al., 1967; Samarina et al., 1968; Walker et al., 1980) or severe mechanical forces (Faiferman and Pogo, 1975; Huang and LeStourgeon, 1994; van Venrooij and Janssen, 1978). DNase I does not release RNP particles, which suggests that the structural associations retaining them in the nucleus are not with chromatin (Herman et al., 1978; Narayan et al., 1967). Vigorous shearing forces are necessary to release RNP particles (Faiferman and Pogo, 1975), and the amount of RNP released correlates well with the degree of nuclear disintegration (van Venrooij and Janssen, 1978). Collectively, this early work demonstrated that the RNP of the nucleus either forms a structure or alternatively is connected to other, nonchromatin, structures.

RNA-selective staining procedures have made a more complete characterization of nuclear RNP network ultrastructure possible (Bernhard, 1969; Biggiogera and Fakan, 1998). Making elegant use of EDTA regressive staining to localize RNA, Monneron and Bernhard were able to define, characterize and classify the interconnected nuclear RNP structures, including interchromatin granule clusters, perichromatin fibrils, perichromatin granules and coiled bodies (Monneron and Bernhard, 1969). These structures loom large in our understanding of nuclear RNA metabolism (Misteli, 2000; Misteli and Spector, 1998). Perichromatin fibrils, for example, are sites of RNA transcription (Bachellerie et al., 1975; Cmarko et al., 1999), whereas interchromatin granule clusters play a central role in RNA splicing (Mintz et al., 1999; Smith et al., 1999).

The RNP network can be seen at high resolution in unstained sections of fixed, unextracted cells by electron spectroscopic imaging (Hendzel et al., 1999). This technique can measure the relative enrichment for protein and nucleic acids in intranuclear structures by imaging the relative elemental abundance of nitrogen and phosphorus. Visualized by this technique, the RNP network has substructures that contain more RNA and other assemblies that are enriched in protein. Some complications in analysis can occur for massively phosphorylated nuclear proteins, but this technique has exposed new ultrastructural details of the RNP network and its proteinaceous subassemblies. A more complete characterization will of course require us to identify specific molecules and localize them within those structures.

\section{Isolation of the nuclear RNP network and its substructures}

The microscopic observation of a nuclear RNP-containing structure was not challenged. The controversy began with the development of procedures to isolate this structure, procedures aimed at achieving a biochemical characterization. The pioneering isolation of a nuclear matrix by Berezney and Coffey (Berezney and Coffey, 1974) was important because it revealed a proteinaceous skeleton in the nucleus that was stable to nuclease digestion. Electron microscopy revealed this structure to consist of fibers connected to a nuclear lamina. This approach used an RNase digestion step and so did not isolate a complete RNP network; rather it revealed an underlying RNase-resistant scaffolding, which might correspond to the high $\mathrm{N}: \mathrm{P}$ ratio structures mentioned above (Hendzel et al., 1999).

When the nuclear matrix is isolated without RNase digestion, RNA can be released from the structure only by subsequent RNase digestion or sheering force (Fey et al., 1986; Herman et al., 1978; van Venrooij and Janssen, 1978). Released RNA is in the form of RNP particles, which have a protein composition and ultrastructure similar to that of those released by mechanical destruction of the nucleus (Berezney, 1980). Matrix-released RNP particles, like those released from nuclei by sonication, remain connected to remnant fibrils (Berezney, 1980).

Several early nuclear matrix isolation protocols were aimed at isolating nuclear RNP structures (Capco et al., 1982; Faiferman and Pogo, 1975; Gallinaro et al., 1983). Other groups attempted to isolate non-chromatin structures and then discovered the RNP network by ultrastructural analysis (Brasch, 1982). All of these nuclear matrix preparations retain ultrastructural features of the RNP network of the unextracted nucleus, and better preparations have relied heavily on ultrastructural criteria during method development (Capco et al., 1982). 
Nuclear matrix preparations should be evaluated by how well they preserve the ultrastructure of the nuclear RNP network. The most straightforward method of assessment is EDTA regressive staining of thin sections, which selectively visualizes RNA structures both in unextracted nuclei and in nuclear matrix preparations. The isolation procedure affording the best ultrastructural preservation uses extensive crosslinking of the nucleus before removal of chromatin with DNase I (Nickerson et al., 1997). This procedure removes $95 \%$ of DNA and histones from the nucleus. The crosslinking allows superior preservation of ultrastructure (Fig. 1B), which is extremely similar to that of the nuclear RNP network observed by selective staining for RNA in unextracted cells (Fig. 1A) (Bernhard, 1969; Biggiogera and Fakan, 1998).

The nuclear matrix consists of two parts: the nuclear lamina and an internal nuclear matrix that is connected to the lamina and fills the nuclear interior (Fig. 2A). This internal matrix is a network of irregular fibers that have an intricate fine structure. Structural remnants of nucleoli are evident in this network. At higher magnification (Fig. 2B), the fibers of the crosslinkstabilized nuclear matrix appear as intricately structured fibers attached to granular material. The fibers are built on a network of branched filaments that lie beneath and protrude from these fibers. If crosslinking is not used (Fig. 3), the network of branched 10-nm filaments is stripped of covering material (He et al., 1990).

The preservation of the nuclear RNP network after the removal of chromatin can be evaluated in selectively stained ultrathin sections prepared by the EDTA regressive method (compare Fig. 1A and Fig. 1B). The nuclear distribution of the RNP network is conserved through the matrix isolation procedure. Higher magnification reveals that the subassemblies of the RNP network are also conserved. For example, in Fig. $1 \mathrm{C}$, a well-preserved interchromatin granule cluster has been immunostained with an antibody against the RNA-splicing factor SRm300 (Blencowe et al., 2000; Blencowe et al., 1994).

Other nuclear matrix preparations show similar ultrastructural features, although they exhibit varying degrees of preservation. Even matrix isolation by a radically different procedure, removing chromatin by electroelution, uncovers a structure that is markedly similar and reveals an underlying network of core filaments (Jackson and Cook, 1988). On the basis of these observations, the laboratories of Penman and Cook proposed that the internal nuclear matrix is constructed

Fig. 1. The RNP network of the nucleus is well preserved after chromatin removal in a nuclear matrix preparation. Shown are CaSki cells prepared for conventional thin section microscopy before (A) and after (B) the isolation of a crosslink-stabilized nuclear matrix and selectively stained for RNA by the EDTA-regressive staining procedure to visualize the RNP network. The nuclear lamina (L) forms the periphery of both nucleus (A) and nuclear matrix (B). The removal of chromatin after formaldehyde crosslinking does not substantially alter the structure or spatial distribution of the nuclear RNP network. (C) Higher magnification reveals well-preserved interchromatin granule clusters, enriched in RNA-splicing factors, in the RNP-network of the crosslink-stabilized nuclear matrix. The CaSki nuclear matrix in this panel was counterstained with an antibody recognizing the RNA-splicing factor SRm160 and a colloidal-gold-conjugated second antibody. Bars: $500 \mathrm{~nm}$ (A and B); 200 nm (C). From Nickerson et al., 1997. Copyright 1997 National Academy of Sciences, USA.

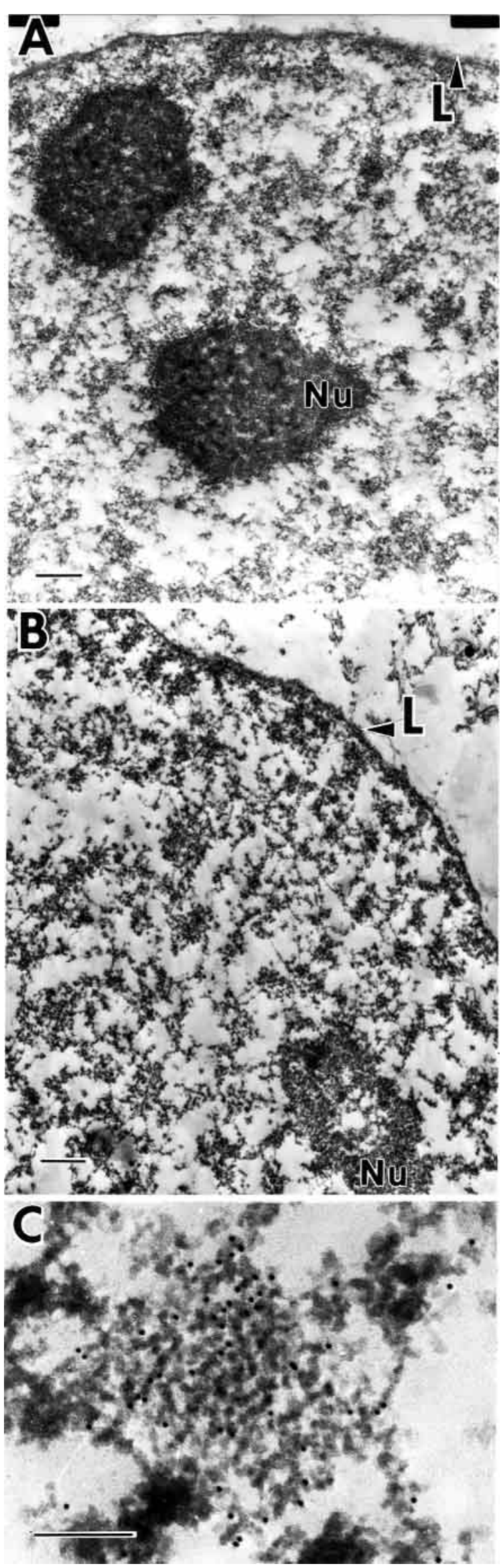


Fig. 2. The nuclear matrix of a CaSki cell prepared by the crosslink-stabilized nuclear matrix preparation procedure and visualized by resinless section electron microscopy. (A) The nuclear matrix consists of two parts: the nuclear lamina (L) and a network of intricately structured fibers connected to the lamina and well distributed through the nuclear volume. The matrices of nucleoli $(\mathrm{Nu})$ remain and are connected to the fibers of the internal nuclear matrix. Three remnant nucleoli may be seen in this section. (B) Seen at higher magnification, the highly structured fibers of the internal nuclear matrix are constructed on an underlying structure of 10-nm filaments, which occasionally branch. These are seen most clearly when, for short stretches, they are free of covering material (arrowheads). Bars: $1 \mu \mathrm{m}$ (A); 100 nm (B). From Nickerson et al., 1997. Copyright 1997 National Academy of Sciences, USA.
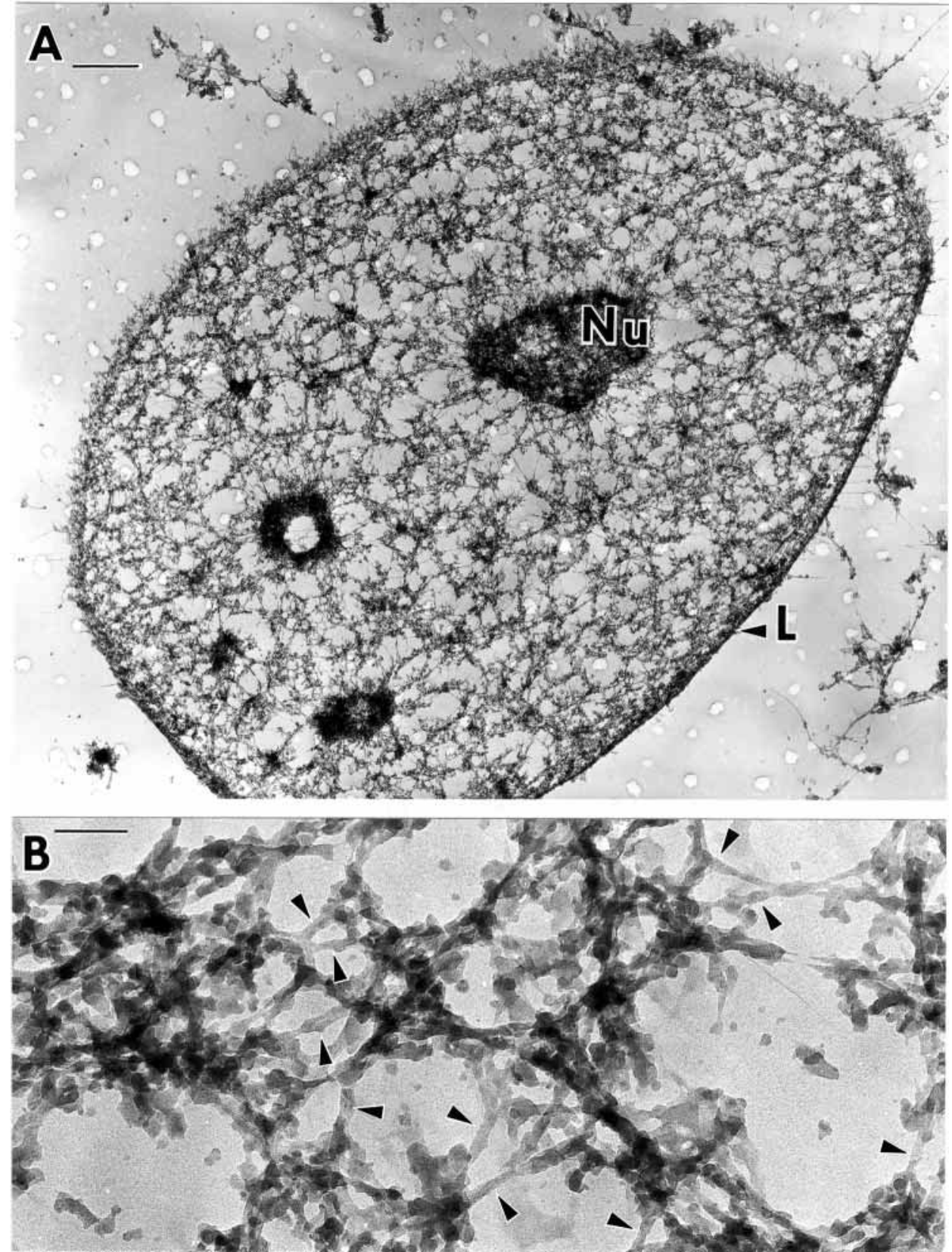

on an underlying network of branched 10-nm filaments that connect to the nuclear lamina (He et al., 1990; Jackson and Cook, 1988; Nickerson et al., 1997). In this model other nuclear matrix components, including hnRNP, are positioned by direct and indirect attachments to $10-\mathrm{nm}$ filaments. These attachments may be dynamic, allowing for considerable plasticity in nuclear architecture and function. Definitive testing of this model of internal nuclear organization will only be possible with a better molecular characterization of $10-\mathrm{nm}$ nuclear filaments, but alternative models of internal nuclear matrix architecture based on ultrastructural observations have not been proposed.

Most nuclear matrix isolation protocols employ non-ionic detergent extraction to remove membranes, deoxyribonuclease digestion to fragment DNA, and hypertonic salt washes to remove the digested DNA. The resulting preparations share similar morphologies, which are preserved to varying degrees. Methods that avoid detergents and/or are performed without hypertonic salt concentrations have been developed (Engelhardt, 1999; Jackson and Cook, 1988; Mirkovitch et al., 1984; Nickerson et al., 1997; Wan et al., 1999) and reveal ultrastructural features similar to those seen in traditional matrix preparations. The ultrastructure of the isolated nuclear matrix cannot, therefore, be ascribed, as critics assert, to $\mathrm{NaCl}$ - or Triton-induced precipitations of nuclear, but not cytoplasmic, proteins (Pederson, 2000).

\section{The attachment of chromatin loops to intranuclear sites}

30-nm chromatin fibers are organized in loops ranging in size from $5 \mathrm{~kb}$ to $200 \mathrm{~kb}$ (Davie, 1995; Nelson et al., 1986; Razin 


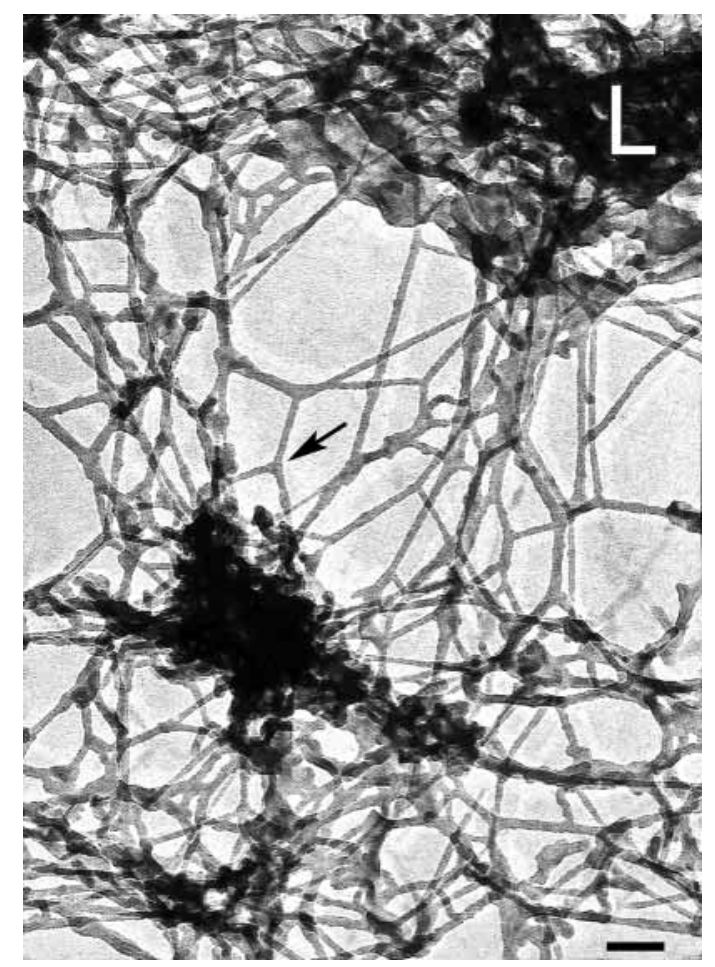

Fig. 3. The 10-nm core filaments of the nuclear matrix prepared from a HeLa cell as in Fig. 2 but without a crosslinking step after the removal of soluble proteins. This more rigorous extraction uncovers the network of branched 10-nm filaments seen in this resinless section electron micrograph. The filaments are almost completely uncovered, unlike the coated core filaments of the crosslinkstabilized nuclear matrix (Fig. 2). This high-magnification view shows connections between core filaments and the nuclear lamina (L). A typical branch structure is marked by the arrow. Bar, $100 \mu \mathrm{m}$. Figure courtesy of D. He and S. Penman.

et al., 1995). Such loops must require structural constraints at their bases. In nuclei, loops are formed by attachments to the nuclear matrix, and a similar loop structure is evident at mitosis, when attachments are made to a proteinaceous chromosomal scaffold.

The existence of chromatin loops was first inferred from measurements of nuclear sedimentation in ethidium bromide at elevated salt concentrations (Benyajati and Worcel, 1976; Cook and Brazell, 1975; Cook et al., 1976). These conclusions were confirmed by the direct microscopic visualization of DNA loops extending far beyond the nuclear lamina after the stripping of histones (Vogelstein et al., 1980). The loops remain anchored to an intranuclear structure and can be wound back into the nucleus by increases in ethidium bromide concentration to levels that induce positive supercoiling. Autoradiography of these preparations, often referred to as halos, from cells pulse labeled with $\left[{ }^{3} \mathrm{H}\right]$ thymidine shows a movement of newly replicated DNA from loop bases to loop peripheries. This suggested that DNA is replicated at the base of chromatin loops by DNA polymerase complexes attached to the nuclear matrix (Pardoll et al., 1980). Replicating DNA loops are reeled through these fixed polymerases. Stably anchored sites of DNA replication have now been observed in living cells (Leonhardt et al., 2000). Time-lapse examination during $\mathrm{S}$ phase shows little movement of replication foci, a result consistent with stable anchoring of replication complexes on a non-chromatin structure. Changes in the $3 \mathrm{D}$ distribution of replication sites occur through disassembly of early sites and new assembly of later sites, not by movement, fusion or fission.

This arrangement of DNA replication complexes, when extrapolated to transcription, suggested that transcribing RNA polymerases are also at fixed sites on the nuclear matrix (Cook, 1999) and solves the topological problem of how a nascent and growing RNA avoids wrapping around its DNA template. Such a hypothesis is increasingly supported by experimental data (Jackson et al., 1998) and places actively transcribed genes at the bases of chromatin loops, close to matrix-attached RNA polymerases. This localization is consistent with a large and older literature showing selective enrichment of active genes at nuclear-matrix-proximal sites. More recently, Gerdes et al. have directly demonstrated the localization of active genes at loop bases by fluorescence in situ hybridization (Gerdes et al., 1994). Many of the enzymes and complexes required for chromatin remodeling and gene activation are also present at nuclear-matrix-associated sites, which may also contain loop bases (Hendzel et al., 1994; Reyes et al., 1997; Sun et al., 1999).

The anchoring of chromatin loops on the nuclear matrix has been studied in considerable molecular detail. Genes contain DNA sequences called matrix-attachment regions (MARs) or scaffold-attachment regions (SARs) that have 150-200 bp subregions that can become single stranded under torsional stress (Bode et al., 1992). MARs are interspersed in the Drosophila genome at intervals of 26,000-112,000 kb (Mirkovitch et al., 1986). This is consistent with the estimated sizes of chromatin loops in flies and mammals (Benyajati and Worcel, 1976; Jackson et al., 1990; Razin et al., 1995; Vogelstein et al., 1980). Binding of MARs to the nuclear matrix usually enhances transcription, but can sometimes repress gene expression (Boulikas, 1995).

MARs bind to specific nuclear matrix and nuclear lamina proteins, of which many are present in all cell types. The bestcharacterized MAR-binding protein, however, is probably SATB1, which is preferentially expressed in thymocytes (Dickinson et al., 1992). SATB1-knockout mice die soon after birth and do not develop T cells (Alvarez et al., 2000). The absence of SATB1 in cells of this lineage causes at least $2 \%$ of all genes to be de-repressed, and this inappropriate expression of genes - including apoptosis-related genes - could block normal $\mathrm{T}$ cell development. SATB1-binding MAR sequences are located at the base of chromatin loops only in cells expressing SATB1 (de Belle et al., 1998). In SATB1-null cells, they are located at the periphery of loops. SATB1binding MARS are retained in nuclear matrix preparations only in cells expressing SATB1.

This cell type specificity of chromatin loop architecture and developmentally programmed gene expression demonstrates the central importance of nuclear-matrix-chromatin interactions in cells. Chromatin-loop bases, at which the RNAcontaining nuclear matrix meets chromatin, are where the important business of the nucleus - DNA replication, gene expression and their regulation - must be conducted.

Interphase chromosomes are organized in discrete and nonoverlapping 3D territories (Cremer et al., 1996). These can be 
identified by FISH with libraries of chromosome-specific sequences. Actively transcribed genes are more likely to be near the periphery of chromosomal territories, which suggests a very high degree of structural organization (Kurz et al., 1996). 400-800-nm subdomains can be identified within chromosomal territories by their property of replicating at the same time during $\mathrm{S}$ phase. These subterritories can be visualized in living cells in which they display a limited movement (Bornfleth et al., 1999). The distribution of chromosomal territories is well preserved in the small fraction of DNA retained at loop bases in nuclear matrix preparations (Ma et al., 1999).

The diversity in nuclear matrix isolation protocols, although yielding complementary results, has spawned some diversity in terminology. Like most of my colleagues, I use the terms nuclear matrix, nuclear scaffold and nucleoskeleton to refer to the same nuclear structure. The term nuclear scaffold was first employed to describe a nuclear structure isolated by digestion of DNA after removal of histones by either $2 \mathrm{M} \mathrm{NaCl}$ or dextran sulfate-heparin (Adolph, 1980). The former is the classic nuclear matrix preparation, but the term nuclear scaffold was later adopted by workers employing $25 \mathrm{mM}$ lithium 3,5-diiodosalicyclate instead of $2 \mathrm{M} \mathrm{NaCl}$ in the removal of chromatin (Mirkovitch et al., 1984) - a procedure reported to preserve molecular interactions at chromatin loop bases better. To these workers, the term scaffold had the advantage of emphasizing the similarity between chromatin loop structure at interphase and at mitosis, when chromatin loops are anchored to a structure termed 'the chromosomal scaffold' (Adolph et al., 1977).

\section{The domain organization of the nucleus survives chromatin removal}

The mapping of the positions of specific molecules by immunostaining, fluorescence in situ hybridization, and pulse labeling has identified a growing number of spatially distinct, functional nuclear domains, including RNA transcription sites, DNA replication sites, speckled domains enriched in RNAsplicing factors, coiled bodies and chromosomal territories (reviewed by Leonhardt and Cardoso, 1995; Nickerson et al., 1995; Spector, 1996). These domains, and their constituent molecules, retain their positions after the removal of the nuclear envelope, soluble proteins and chromatin. The domains observed in nuclear matrix preparations by confocal or electron microscopy are not collapsed against the lamina and are not floating free. They are retained in a precise 3D relationship to other nuclear landmarks, which must be accomplished by a structure. Most domains correspond to structures that can be observed by electron microscopy in unfractionated nuclei and in nuclear matrix preparations.

Fixed DNA-replication sites have been observed in living cells stably expressing low levels of PCNA fused to GFP (Leonhardt et al., 2000). These sites and the machinery required for replication are retained in an unchanged spatial distribution in matrix preparations (Berezney and Wei, 1998; Hozak et al., 1993; Nakayasu and Berezney, 1989; Smith et al., 1984; Tubo and Berezney, 1987; Tubo et al., 1987). The same is true of transcription sites. More than 2000 transcription sites can be observed after pulse labeling of cultured mammalian cells (Jackson et al., 1998; Wansink et al., 1993; Wei et al., 1999). These transcription sites, including newly transcribed
RNA, RNA polymerases I and II, and various transcription factors, retain their $3 \mathrm{D}$ distribution in nuclear matrix preparations (Dickinson et al., 1990; Jackson and Cook, 1985; Mancini et al., 1999; Stenoien et al., 2000a; van Wijnen et al., 1993; Wansink et al., 1996; Wei et al., 1999; Xing and Lawrence, 1991; Zeng et al., 1997).

The speckled domain is another class of subnuclear structure that associates with the nuclear matrix. Speckled domains are highly enriched in molecules involved in RNA splicing. Readily detected by immunofluorescent localization of RNAsplicing factors, they correspond in large part to the interchromatin granule clusters previously observed by electron microscopy in unfractionated cells (Monneron and Bernhard, 1969; Spector, 1996). In nuclear matrix preparations, the ultrastructure and intranuclear positions of these structures are well conserved after the removal of chromatin by DNase I (Nickerson et al., 1997), and RNAsplicing factors are retained. Spector and co-workers have isolated interchromatin granule clusters from nuclear matrix preparations (Mintz et al., 1999). Protein mass spectrometry of these isolated nuclear matrix substructures reveals many proteins involved in RNA splicing and packaging. RNA splicing itself can occur on nuclear-matrix-associated spliceosomal complexes (Zeitlin et al., 1987; Zeitlin et al., 1989). Preassembled complexes containing full-length mRNA precursors are retained in nuclear matrix preparations and will splice out introns in situ upon addition of ATP. The nuclear matrix proteins SRm160 and SRm300, which are required for some in vitro RNA-splicing reactions, are localized to interchromatin granule clusters and might bridge dynamic interactions between splicing complexes and the matrix (Blencowe et al., 2000; Blencowe et al., 1998; Blencowe et al., 1994).

\section{Observations of a nuclear matrix in living cells}

The four pillars of nuclear matrix research discussed above are buttressed by additional research that has increasingly employed live cells. The Drosophila proteins CP60 and CP190 shuttle between the nucleus and centrosomes in a cell-cycledependent way (Oegema et al., 1997). Both are nuclear matrix proteins, as judged by their retention after the removal of chromatin. In living embryos, both fluorescently tagged proteins are observed in fibrous material by wide-field 3D microscopy (Oegema et al., 1997). Fibers containing the respective proteins are not coincident, but occasionally overlap, and they do not co-localize with DNA. These fibrous networks persist in mitosis, when they become spatially separated from chromosomes; their fibrous appearance is therefore not 'channeling' caused by exclusion from regions of nuclear chromatin. The targeting of CP60 to fibrous extrachromosomal structures requires another protein, EAST, which controls the size of an expandable, extrachromosomal domain (Wasser and Chia, 2000). The protein Skeletor may be another component of this fibrous Drosophila nucleoskeleton (Johansen et al., 1999). Another novel approach to the study of nuclear structure is micromanipulation of nuclear structures in living cells (Maniotis et al., 1997), which has shown that subnuclear structures and interphase chromosomes are all connected.

\section{Structural molecules of the nuclear matrix}

Although we have characterized the ultrastructure of the 
internal nuclear matrix and its subassemblies, we know much less about their major structural molecules. Many nuclear matrix proteins have been identified and sequenced, but we do not know where or how they assemble into structures. This is a problem that will hobble future research until we address it with the combined application of biochemistry and electron microscopy.

The protein composition of the nuclear matrix is quite different from that of other cellular or nuclear fractions (Capco et al., 1982). Nuclear matrix preparations examined by 2D gel electrophoresis typically reveal 200 major protein spots. A subset of these proteins is cell-type specific, whereas the expression of others correlates with malignant progression (Fey and Penman, 1988; Getzenberg et al., 1991). The nuclear lamina, contains three major structural proteins: lamin A, lamin $\mathrm{B}$ and lamin $\mathrm{C}$. Additional proteins connect the lamina to the nuclear envelope and to heterochromatin clustered at the nuclear periphery (Goldberg et al., 1999; Gruenbaum et al., 2000). Our understanding of the molecular architecture of the internal nuclear matrix is less advanced; only a few proteins have been localized by electron microscopy, and only a few protein-protein interactions are known.

Van Driel and colleagues (Mattern et al., 1996) identified a subset of nuclear matrix proteins released by the application of $2 \mathrm{M} \mathrm{NaCl}$, RNase A and dithiothreitol. Analyzed by 2D electrophoresis, the principal proteins were identified as hnRNP proteins and the nucleolar protein B23. This is hardly surprising, given the identity of the nuclear matrix as an RNPcontaining structure. The ultrastructure of the crosslinkstabilized nuclear matrix (Nickerson et al., 1997) and the localization of hnRNP core proteins relative to filaments (He et al., 1991) suggests a model in which assemblies of hnRNP are attached to the underlying armature of branched $10-\mathrm{nm}$ filaments (see above).

The characterization of $10-\mathrm{nm}$ core filament composition is the central problem in nuclear matrix structure. Several proteins have been proposed to be core filament proteins but, so far, none has been elected as a principal structural component of the filaments. Lamins can be detected at sites along nuclear filaments (Hozak et al., 1995), but the distribution of sites and low level of staining suggest that they are not the structural core. An antibody against NuMA labels a subfraction $(\sim 15 \%)$ of nuclear filaments (He et al., 1995), This leaves a majority of core filaments unaccounted for. In addition, three other anti-NuMA antibodies readily label the nuclear matrix but not on 10-nm filaments (J. Nickerson, G. Krockmalnic, and S. Penman, unpublished results). NuMA can self assemble into multi-arm oligomers both in vitro and after overexpression in cells (Gueth-Hallonet et al., 1998; Harborth et al., 1999) and, therefore, seems a promising candidate for a structural protein that has a different role in nuclear architecture.

Recently, Tan et al. reported that sonicated RNP remnants can be induced to assemble into filaments that could contain the hnRNP proteins A2 and/or B1 and that these might be the core filaments (Tan et al., 2000). Reassembled hnRNP A2/B1 filaments are 7-18 $\mathrm{nm}$ in diameter and are helical, with a pitch of $60 \mathrm{~nm}$. In the nucleus, 10-nm core filaments are not helical and, like intermediate filaments, have an axial repeat of $23 \mathrm{~nm}$ (Jackson and Cook, 1988). Of course, these differences in form might be attributable to the highly artifactual nature of high- energy sonication, isolation and reassembly. Nevertheless, an antibody that recognizes a shared epitope on hnRNP core proteins, including A2/B1 (Leser et al., 1984), does not stain core filaments (He et al., 1991). Although localization of hnRNP A2/B1 with additional antibodies should be - and is being - done, it seems unlikely that hnRNP A2 and hnRNP B1 are principal core filament constituents.

A growing number of proteins known to play roles in cytoarchitecture are being found in the nucleus and nuclear matrix. Especially interesting are nuclear actin (Capco et al., 1982) and a large number of actin-binding proteins (Rando et al., 2000). Some of this nuclear actin might be in filamentous form (Amankwah and De Boni, 1994). Actin-related nuclear proteins include myosin and structural protein 4.1 (Krauss et al., 1997; Nowak et al., 1997), which can bind to NuMA (Mattagajasingh et al., 1999). This interaction could link actinrelated nuclear structures to NuMA-related structures. Although the role of actin in the nuclear matrix remains mysterious, there have been hints of an interaction between nuclear actin and nuclear RNAs (Nakayasu and Ueda, 1985; Schroder et al., 1987). More recently, actin and several actinrelated proteins have been found in chromatin-remodeling complexes (Rando et al., 2000).

Proteins may not be the only non-chromatin structural molecules in the nucleus. The nuclear matrix retains most nuclear RNA, some of which may be a structural determinant of higher-order chromatin architecture (Nickerson et al., 1995). Intact RNA and the continuing synthesis of RNA are required for normal chromatin structure. Digestion with ribonucleases or treatment of either cultured cells or animals with RNA polymerase II inhibitors causes the collapse of chromatin into progressively larger masses of heterochromatin-like material (Derenzini et al., 1976; Derenzini et al., 1981; Nickerson et al., 1995; Nickerson et al., 1989). A great deal of the hnRNA of the nucleus is not a precursor for mRNA, and some of this could structure chromatin. One example of a specific nuclearmatrix-associated and non-protein-coding hnRNA that has a proven role in higher-order chromatin structure and epigenetic regulation is XIST, a polyadenylated RNA that functions in the structural inactivation of all but one $\mathrm{X}$ chromosome in female mammalian cells (Clemson et al., 1996; Panning and Jaenisch, 1998).

\section{Nuclear dynamics}

It has long been suggested that the nuclear matrix is a highly dynamic structure (Berezney, 1979). Recently, however, the existence of a nuclear matrix has been questioned, in part, because some components of the nucleus are dynamic (Pederson, 2000). A powerful approach for measuring the dynamics of subnuclear structures and molecules is to track fluorescently tagged molecules in living nuclei. Time-lapse studies can characterize the plasticity of the structures in which those molecules are incorporated. The binding parameters of individual molecules with those structures are better determined by laser photobleaching techniques (Kruhlak et al., 2000; Phair and Misteli, 2000). Current results suggest that nuclear substructures - such as interchromatin granule clusters or DNA replication sites - are interconnected with the nuclear matrix and have relatively fixed positions; they move only over time periods of 10 minutes to several hours. Some of the molecules present in these structures, however, may be in more 
rapid equilibrium with smaller and more soluble nucleoplasmic pools.

All structures that are not covalently crosslinked must arise from dynamic interactions between constituent molecules. These can be equilibrium or steady-state interactions, but there are always at least two pools of molecules: free and bound. Molecules will move at diffusion rates when free and at the same rate as the structure when bound. Taking advantage of this difference, photobleaching-recovery techniques can help characterize the binding equilibria for molecules docking on a simple, stable structure. The analysis becomes complicated if the protein has multiple and heterogenous interactions.

\section{Chromatin dynamics}

Abney et al. showed, using a DNA-intercalating dye, that the positions of photobleached 400-nm-diameter regions of chromatin change little in one hour (Abney et al., 1997). Timelapse studies indicate that, over shorter periods, fluorescently tagged chromosomal subterritories 400-800 $\mathrm{nm}$ in diameter have a limited range of random motion (Bornfleth et al., 1999). Together, these results suggest that small regions of chromatin are flexibly tethered to relatively immobile sites. Chromatin proteins can have very different rates of photobleaching recovery (Phair and Misteli, 2000). Histone H2B-GFP does not substantially recover over periods of several minutes, whereas HMG-17 has a surprisingly rapid recovery. This suggests that the exchange of HMG-17 on chromatin is much more facile than that of the histone. The result does not show that HMG17 is unassociated with a nuclear structure (chromatin).

\section{RNA dynamics}

The dynamics of nuclear RNA are more contested. Ribonuclease digestion or severe sheering force is required to release most nuclear RNA. Nevertheless, Pederson proposes that the larger fraction of nuclear polyadenylated RNA diffuses (Pederson, 2000). This view is based on the measured mobility of fluorescently tagged oligo-dT in the nucleus of cultured cells (Politz et al., 1998; Politz et al., 1999). A majority of this nucleotide moves at rates approaching that of diffusion, whereas a smaller fraction is more static. If the fraction of oligo-dT in each population that is actually hybridized to polyadenylated nuclear RNA in the living cell could be determined, then this experimental approach would tell us something important about nuclear RNA dynamics.

Localization of specific polyadenylated RNAs in fixed nuclei by FISH with intron and exon probes identifies highly localized, nuclear-matrix-associated, non-diffusing populations (Smith et al., 1999; Xing and Lawrence, 1991). These results suggest a model in which newly transcribed mRNA is processed in and constrained to small nuclear sites, even immediately after splicing. These are relatively slow steps, and considerable accumulation results. Then, in a more rapid step, RNA is released from these sites and moves to nuclear pores for export. The mechanism of movement to pores is unknown, although both diffusion and directed transport mechanisms have been proposed (Miralles et al., 2000; Singh et al., 1999).

\section{Nuclear protein dynamics}

Several studies have examined the dynamics of nuclear GFP fusion proteins. Unfortunately, photobleaching studies have not yet been done on molecules proposed to play a major role in nuclear matrix structure - for example, actin, NuMA and EAST - but have focused on proteins involved in transcription or DNA replication. Most current experiments use transiently overexpressed GFP fusion proteins. The resulting measurements are meaningful only if the number of GFP fusion protein molecules plus the number of endogenous molecules is considerably smaller than the number of available binding sites. If the binding sites are saturated, the excess protein will tend to be highly mobile (Kruhlak et al., 2000; Shopland and Lawrence, 2000). In some studies, it is impossible to evaluate whether this condition is met. In a study careful to avoid this pitfall, Leonhardt et al. observed DNA replication sites in time-lapse studies of living cells stably expressing low levels of PCNA-GFP (Leonhardt et al., 2000). As discussed earlier, these sites have very restricted mobility, which is consistent with stable anchoring of replication complexes to fixed sites on the nuclear matrix.

Fluorescence tagging of transcription factors bound to promoters has provided additional insight into nuclear protein dynamics. The estrogen receptor $\alpha$ (ER $\alpha)$-GFP fusion, for example, has a diffuse nuclear pattern in the absence of ligand and is soluble. After addition of estrogen, it becomes concentrated in discrete nuclear sites and becomes nuclear matrix bound (Stenoien et al., 2000a). Recent photobleaching experiments by Mancini et al. have shown that ER $\alpha$ dynamics are regulated by ligand, cellular ATP levels, and proteosomal inhibition (Stenoien et al., 2000b). Unliganded ER $\alpha$ is highly mobile (recovery $\mathrm{t} 1 / 2=1$ second). Estradiol binding decreases the mobility $\left(\mathrm{t}_{1} / 2=8\right.$ seconds), and this effect correlates with increased matrix binding. Binding of the estrogen antagonist ICI 182,789 or treatment of cells with proteasomal inhibitors almost stops exchange ( $t \frac{1}{2}=5-20$ minutes $)$. The glucocorticoid receptor, when bound to chromatin, undergoes rapid exchange with an unbound pool of receptor (McNally et al., 2000).

GFP fused to the RNA-splicing factor ASF/SF2 localizes to speckles. These splicing speckles, seen by light microscopy, correspond to the interchromatin granule clusters observed as nuclear-matrix-associated structures by electron microscopy (Fig. 1C). Two independent FRAP measurements show that GFP-ASF/SF2 fluorescence recovers only two orders of magnitude slower than the rate of GFP diffusion (Phair and Misteli, 2000; Kruhlak et al., 2000). There are, however, two different interpretations of this common result. The first is that ASF/SF2 moves so rapidly through the nucleus that this protein is unlikely to interact with any stable nuclear structure (Pederson, 2000). The second interpretation is that ASF/SF2 is slowed by transient binding to a relatively immobile nuclear matrix (Kruhlak et al., 2000). In the simplest case, GFPASF/SF2 would be relatively immobile when bound to interchromatin granule clusters but moving at diffusion rates when free.

Splicing speckles labeled with GFP-ASF/SF2 can, over periods of ten minutes to several hours, move within the nucleus, bud and fuse (Misteli et al., 1997). They can also move in a directed way to new sites of high-level RNA transcription. This movement is, however, much slower than the movement through the nucleoplasm of artificially induced structures of similar size, which do not interact with the nuclear matrix (Kruhlak et al., 2000). In all photobleaching experiments with ASF/SF2-GFP, recovery of fluorescence reveals the same 
speckle distribution present before bleaching (Kruhlak et al., 2000; Phair and Misteli, 2000). Thus, the association of ASF/SF2-GFP with speckles is much more dynamic than speckle structure and position. This is consistent with ASF/SF2-GFP having rapid transient interactions with a matrix-associated interchromatin granule cluster that is very slowly remodeling.

The behavior of some proteins in photobleaching experiments presents a paradox. ASF/SF2 is a good example. Photobleaching results suggest that ASF/SF2 rapidly exchanges between binding sites on interchromatin granule clusters and a soluble pool. However, this protein does not diffuse away when barriers to that diffusion, the nuclear and cell membranes, are removed. When these membranes are removed by non-ionic detergent extraction, splicing factors, including ASF/SF2, do not diffuse away (Misteli and Spector, 1996; Shopland and Lawrence, 2000; J. Nickerson, unpublished observations). Splicing speckles (interchromatin granule clusters) do not require soluble factors for their maintenance (Misteli and Spector, 1996), are maintained for 18 hours after permeabilization (Shopland and Lawrence, 2000), and do not lose splicing factors after mechanical disruption of the nucleus (Shopland and Lawrence, 2000). A majority of ASF/SF2 remains in speckles after $0.1 \%$ Triton X-100 extraction (Misteli and Spector, 1996) and after $0.5 \%$ Triton X-100 extraction (J. Nickerson, unpublished observations).

Interchromatin granule clusters have been isolated from nuclear matrix preparations (Mintz et al., 1999). The purification protocol requires many extractions, incubations, washes and cesium sulfate centrifugations. After all these opportunities to escape by free diffusion, ASF/SF2 is a major protein identified in these isolated structures by both western blotting and protein mass spectrometry (Mintz et al., 1999). All these results in disrupted or extracted cells suggest slow exchange between structure-associated and nucleoplasmic pools.

The inconsistency between the dynamics of ASF/SF2 in live cells and those in dead or fractionated cells could be resolved if the rapid exchange of ASF/SF2 between IGC-associated and soluble sites were regulated by soluble factors lost after cell disruption. Obvious candidates for such factors are protein kinases and ATP. One study attempted to rule this out by reducing cellular ATP levels before photobleaching (Phair and Misteli, 2000). Although it may be mis-stated, the cited method may not cause sufficient ATP reduction and, in any case, cellular ATP levels were not measured. It is too early to rule out an involvement of protein phosphorylation. A second possibility might involve glutathione and sulfhydryl groups. Agents promoting disulfide bond formation could stabilize nuclear structures, whereas sulfhydryl reducing agents could destabilize them (Kaufmann and Shaper, 1984; Mattern et al., 1996).

\section{Conclusion}

Sometimes seeing is believing. Overwhelming evidence for a non-chromatin structure in the nucleus comes from direct microscopic observation. Additional strong experimental evidence should convince us that this nuclear matrix provides an architectural support for higher-order chromatin packaging and for the central processes of nucleic acid metabolism. Our greatest area of ignorance is the identity of the architectural molecules that assemble into the structures that we have seen for many years with our microscopes. Although we have identified many nuclear matrix proteins, we do not yet know how they fit together into the fibers, filaments and assemblies of the structure. This deficiency can be addressed only by the combined application of biochemistry and microscopy. Doing so is an important goal because structure is the organizing principle of the cell. The cell spatially organizes the incipient chaos of nuclear metabolism by structuring it on a matrix. So too, thinking about a nuclear matrix helps us intellectually to organize the vast, growing and overwhelming experimental data on nucleic acids biochemistry.

Anything static is certainly dead. With our growing power to manipulate live cells, we observe the nucleus as a dynamic organelle. Intranuclear structures, such as chromatin or nuclear matrix subassemblies, move slowly, while their constituent molecules are in more rapid equilibrium with nucleoplasmic pools. The non-chromatin structures of the nucleus were first observed in fixed sections, and, in that form, these structures were both static and dead. Although the major structural proteins of the nuclear matrix have not yet been tracked in live cells, current evidence forces us, like Galileo, to remark, 'Epur si muove' [And yet it does move].

I thank S. Penman for his comments and encouragement as well as M. Marcini, B. Blencowe, and S. Wagner for discussions that clarified many issues. I regret that space limitations have made it impossible to cite many contributors to our understanding of the nuclear matrix.

\section{References}

Abney, J. R., Cutler, B., Fillbach, M. L., Axelrod, D. and Scalettar, B. A. (1997). Chromatin dynamics in interphase nuclei and its implications for nuclear structure. J. Cell Biol. 137, 1459-1468.

Adolph, K. W., Cheng, S. M., Paulson, J. R. and Laemmli, U. K. (1977). Isolation of a protein scaffold from mitotic HeLa cell chromosomes. Proc. Nat. Acad. Sci. USA 74, 4937-4941.

Adolph, K. W. (1980). Organization of chromosomes in HeLa cells: isolation of histone-depleted nuclei and nuclear scaffolds. J. Cell Sci. 42, 291-304.

Alvarez, J. D., Yasui, D. H., Niida, H., Joh, T., Loh, D. Y. and KohwiShigematsu, T. (2000). The MAR-binding protein SATB1 orchestrates temporal and spatial expression of multiple genes during T-cell development. Genes Dev. 14, 521-535.

Amankwah, K. S. and De Boni, U. (1994). Ultrastructural localization of filamentous actin within neuronal interphase nuclei in situ. Exp. Cell Res. 210, 315-325.

Bachellerie, J. P., Puvion, E. and Zalta, J. P. (1975). Ultrastructural organization and biochemical characterization of chromatin - RNA - protein complexes isolated from mammalian cell nuclei. Eur. J. Biochem. 58, 327337.

Benyajati, C. and Worcel, A. (1976). Isolation, characterization, and structure of the folded interphase genome of Drosophila melanogaster. Cell 9, 393407.

Berezney, R. and Coffey, D. S. (1974). Identification of a nuclear protein matrix. Biochem. Biophys. Res. Commun. 60, 1410-1417.

Berezney, R. (1979). Dynamic properties of the nuclear matrix. In The Cell Nucleus, vol. 7 (ed. H. Busch), pp. 413-456. Orlando: Academic Press.

Berezney, R. (1980). Fractionation of the nuclear matrix. I. Partial separation into matrix protein fibrils and a residual ribonucleoprotein fraction. J. Cell Biol. 85, 641-650.

Berezney, R. (1984). Organization and functions of the nuclear matrix. In Chromosomal Nonhistone Proteins, vol. IV (ed. L. S. Hnilica), pp. 119-180. Boca Raton, FL: CRC Press.

Berezney, R. and Wei, X. (1998). The new paradigm: integrating genomic function and nuclear architecture. J. Cell. Biochem. (suppl.) 31, 238-242.

Bernhard, W. (1969). A new staining procedure for electron microscopical cytology. J. Ultrastruct. Res. 27, 250-265. 
Biggiogera, M. and Fakan, S. (1998). Fine structural specific visualization of RNA on ultrathin sections. J. Histochem. Cytochem. 46, 389-395.

Blencowe, B. J., Bauren, G., Eldridge, A. G., Issner, R., Nickerson, J. A., Rosonina, E. and Sharp, P. A. (2000). The SRm160/300 splicing coactivator subunits. RNA 6, 111-120.

Blencowe, B. J., Nickerson, J. A., Issner, R., Penman, S. and Sharp, P. A. (1994). Association of nuclear matrix antigens with exon-containing splicing complexes. J. Cell Biol. 127, 593-607.

Blencowe, B. J., Issner, R., Nickerson, J. A. and Sharp, P. A. (1998). A coactivator of pre-mRNA splicing. Genes Dev. 12, 996-1009.

Bode, J., Kohwi, Y., Dickinson, L., Joh, T., Klehr, D., Mielke, C. and Kohwi-Shigematsu, T. (1992). Biological significance of unwinding capability of nuclear matrix-associating DNAs. Science 255, 195-197.

Bornfleth, H., Edelmann, P., Zink, D., Cremer, T. and Cremer, C. (1999). Quantitative motion analysis of subchromosomal foci in living cells using four-dimensional microscopy. Biophys. J. 77, 2871-2886.

Boulikas, T. (1995). Chromatin domains and prediction of MAR sequences. Int. Rev. Cytol. 162A, 279-388.

Brasch, K. (1982). Fine structure and localization of the nuclear matrix in situ. Exp. Cell Res. 140, 161-171.

Capco, D. G., Wan, K. M. and Penman, S. (1982). The nuclear matrix: threedimensional architecture and protein composition. Cell 29, 847-858.

Clemson, C. M., McNeil, J. A., Willard, H. F. and Lawrence, J. B. (1996). XIST RNA paints the inactive X chromosome at interphase: evidence for a novel RNA involved in nuclear/chromosome structure. J. Cell Biol. 132, 259-275.

Cmarko, D., Verschure, P. J., Martin, T. E., Dahmus, M. E., Krause, S., Fu, X. D., van Driel, R. and Fakan, S. (1999). Ultrastructural analysis of transcription and splicing in the cell nucleus after bromo-UTP microinjection. Mol. Biol. Cell 10, 211-223.

Cook, P. R. and Brazell, I. A. (1975). Supercoils in human DNA. J. Cell Sci. 19, 261-279.

Cook, P. R., Brazell, I. A. and Jost, E. (1976). Characterization of nuclear structures containing superhelical DNA. J. Cell Sci. 22, 303-324.

Cook, P. R. (1999). The organization of replication and transcription. Science 284, 1790-1795.

Cremer, C., Munkel, C., Granzow, M., Jauch, A., Dietzel, S., Eils, R., Guan, X. Y., Meltzer, P. S., Trent, J. M., Langowski, J. et al. (1996) Nuclear architecture and the induction of chromosomal aberrations. Mutat. Res. 366, 97-116.

Davie, J. R. (1995). The nuclear matrix and the regulation of chromatin organization and function. Int. Rev. Cytol. 191-250.

de Belle, I., Cai, S. and Kohwi-Shigematsu, T. (1998). The genomic sequences bound to special AT-rich sequence-binding protein 1 (SATB1) in vivo in Jurkat $\mathrm{T}$ cells are tightly associated with the nuclear matrix at the bases of the chromatin loops. J. Cell Biol. 141, 335-348.

Derenzini, M., Marinozzi, V. and Novello, F. (1976). Effects of alphaamanitine on chromatin in regenerating rat hepatocytes: a biochemical and morphologic study. Virchows Arch. B Cell. Pathol. 20, 307-318.

Derenzini, M., Pession-Brizzi, A., Betts-Eusebi, C. and Novello, F. (1981). Relationship between the fine structural organization of chromatin and nucleic acid synthesis in regenerating rat hepatocytes. J. Ultrastruct. Res. 75, 229-242.

Dickinson, P., Cook, P. R. and Jackson, D. A. (1990). Active RNA polymerase I is fixed within the nucleus of HeLa cells. EMBO J. 9, 22072214.

Dickinson, L. A., Joh, T., Kohwi, Y. and Kohwi-Shigematsu, T. (1992). A tissue-specific MAR/SAR DNA-binding protein with unusual binding site recognition. Cell 70, 631-645.

Engelhardt, M. (1999). Demonstration of a DNase-sensitive network associated with the nuclear pore complexes in rat liver nuclei. Chromosoma 108, 64-71.

Faiferman, I. and Pogo, A. O. (1975). Isolation of a nuclear ribonucleoprotein network that contains heterogeneous RNA and is bound to the nuclear envelope. Biochemistry 14, 3808-3816.

Fawcett, D. W. (1966). An Atlas of Fine Structure: The Cell, Its Organelles and Inclusions. Philadelphia: W. B. Saunders Co.

Fey, E. G., Ornelles, D. A. and Penman, S. (1986). Association of RNA with the cytoskeleton and the nuclear matrix. J. Cell Sci. Suppl. 5, 99-119.

Fey, E. G. and Penman, S. (1988). Nuclear matrix proteins reflect cell type of origin in cultured human cells. Proc. Nat. Acad. Sci. USA 85, 121125 .

Gallinaro, H., Puvion, E., Kister, L. and Jacob, M. (1983). Nuclear matrix and hnRNP share a common structural constituent associated with premessenger RNA. EMBO J. 2, 953-960.

Gerdes, M. G., Carter, K. C., Moen, P. T. Jr and Lawrence, J. B. (1994) Dynamic changes in the higher-level chromatin organization of specific sequences revealed by in situ hybridization to nuclear halos. J. Cell Biol. 126, 289-304.

Getzenberg, R. H., Pienta, K. J., Huang, E. Y. and Coffey, D. S. (1991). Identification of nuclear matrix proteins in the cancer and normal rat prostate. Cancer Res. 51, 6514-6520.

Goldberg, M., Harel, A. and Gruenbaum, Y. (1999). The nuclear lamina: molecular organization and interaction with chromatin. Crit. Rev. Eukaryot. Gene Expr. 9, 285-293.

Gruenbaum, Y., Wilson, K. L., Harel, A., Goldberg, M. and Cohen, M. (2000). Review: nuclear lamins-structural proteins with fundamental functions. J. Struct. Biol. 129, 313-323.

Gueth-Hallonet, C., Wang, J., Harborth, J., Weber, K. and Osborn, M. (1998). Induction of a regular nuclear lattice by overexpression of NuMA. Exp. Cell Res. 243, 434-452.

Harborth, J., Wang, J., Gueth-Hallonet, C., Weber, K. and Osborn, M. (1999). Self assembly of NuMA: multiarm oligomers as structural units of a nuclear lattice. $E M B O J .18,1689-1700$.

He, D. C., Nickerson, J. A. and Penman, S. (1990). Core filaments of the nuclear matrix. J. Cell Biol. 110, 569-580.

He, D. C., Martin, T. and Penman, S. (1991). Localization of heterogeneous nuclear ribonucleoprotein in the interphase nuclear matrix core filaments and on perichromosomal filaments at mitosis. Proc. Nat. Acad. Sci. USA 88, 7469-7473.

He, D., Zeng, C. and Brinkley, B. R. (1995). Nuclear matrix proteins as structural and functional components of the mitotic apparatus. Int. Rev. Cytol. 1-74.

Hendzel, M. J., Sun, J. M., Chen, H. Y., Rattner, J. B. and Davie, J. R. (1994). Histone acetyltransferase is associated with the nuclear matrix. $J$. Biol. Chem. 269, 22894-22901.

Hendzel, M. J., Boisvert, F. and Bazett-Jones, D. P. (1999). Direct visualization of a protein nuclear architecture. Mol. Biol. Cell 10, 20512062.

Herman, R., Weymouth, L. and Penman, S. (1978). Heterogeneous nuclear RNA-protein fibers in chromatin-depleted nuclei. J. Cell Biol. 78 663-674.

Hozak, P., Hassan, A. B., Jackson, D. A. and Cook, P. R. (1993). Visualization of replication factories attached to nucleoskeleton. Cell $\mathbf{7 3}$, 361-373.

Hozak, P., Sasseville, A. M., Raymond, Y. and Cook, P. R. (1995). Lamin proteins form an internal nucleoskeleton as well as a peripheral lamina in human cells. J. Cell Sci. 108, 635-644.

Huang, M. and LeStourgeon, W. M. (1994). Rapid preparation of hnRNP core proteins and stepwise assembly of hnRNP particles in vitro. In Cell Biology: A Laboratory Handbook, vol. 1 (ed. J. Celis), pp. 641-656. San Diego: Academic Press.

Jackson, D. A. and Cook, P. R. (1985). Transcription occurs at a nucleoskeleton. EMBO J. 4, 919-925.

Jackson, D. A. and Cook, P. R. (1988). Visualization of a filamentous nucleoskeleton with a $23 \mathrm{~nm}$ axial repeat. EMBO J. 7, 3667-3677.

Jackson, D. A., Dickinson, P. and Cook, P. R. (1990). The size of chromatin loops in HeLa cells. EMBO J. 9, 567-571.

Jackson, D. A., Iborra, F. J., Manders, E. M. and Cook, P. R. (1998) Numbers and organization of RNA polymerases, nascent transcripts, and transcription units in HeLa nuclei. Mol. Biol. Cell 9, 1523-1536.

Johansen, K. M., Johansen, J., Jin, Y., Walker, D. L., Wang, D. and Wang, Y. (1999). Chromatin structure and nuclear remodeling. Crit. Rev. Euk. Gene Exp. 9, 267-277.

Kaufmann, S. H. and Shaper, J. H. (1984). A subset of non-histone nuclear proteins reversibly stabilized by the sulfhydryl cross-linking reagent tetrathionate. Polypeptides of the internal nuclear matrix. Exp. Cell Res. 155, 477-495.

Krauss, S. W., Larabell, C. A., Lockett, S., Gascard, P., Penman, S., Mohandas, N. and Chasis, J. A. (1997). Structural protein 4. 1 in the nucleus of human cells: dynamic rearrangements during cell division. J. Cell Biol. 137, 275-289.

Kruhlak, M. J., Lever, M. A., Fischle, W., Verdin, E., Bazett-Jones, D. P. and Hendzel, M. J. (2000). Reduced Mobility of the Alternate Splicing Factor (ASF) through the Nucleoplasm and Steady State Speckle Compartments. J. Cell Biol. 150, 41-52.

Kurz, A., Lampel, S., Nickolenko, J. E., Bradl, J., Benner, A., Zirbel, R. 
M., Cremer, T. and Lichter, P. (1996). Active and inactive genes localize preferentially in the periphery of chromosome territories. J. Cell Biol. 135, 1195-205.

Leonhardt, H. and Cardoso, M. C. (1995). Targeting and association of proteins with functional domains in the nucleus: the insoluble solution. Int. Rev. Cytol. 303-335.

Leonhardt, H., Rahn, H. P., Weinzierl, P., Sporbert, A., Cremer, T., Zink, D. and Cardoso, M. C. (2000). Dynamics of DNA replication factories in living cells. J. Cell Biol. 149, 271-280.

Leser, G. P., Escara-Wilke, J. and Martin, T. E. (1984). Monoclonal antibodies to heterogeneous nuclear RNA-protein complexes. The core proteins comprise a conserved group of related polypeptides. J. Biol. Chem. 259, 1827-1833.

Ma, H., Siegel, A. J. and Berezney, R. (1999). Association of chromosome territories with the nuclear matrix. Disruption of human chromosome territories correlates with the release of a subset of nuclear matrix proteins. J. Cell Biol. 146, 531-542.

Mancini, M. G., Liu, B., Sharp, Z. D. and Mancini, M. A. (1999). Subnuclear partitioning and functional regulation of the Pit-1 transcription factor. J. Cell. Biochem. 72, 322-338.

Maniotis, A. J., Bojanowski, K. and Ingber, D. E. (1997). Mechanical continuity and reversible chromosome disassembly within intact genomes removed from living cells. J. Cell. Biochem. 65, 114-130.

Mattagajasingh, S. N., Huang, S. C., Hartenstein, J. S., Snyder, M., Marchesi, V. T. and Benz, E. J. (1999). A nonerythroid isoform of protein 4. 1R interacts with the nuclear mitotic apparatus (NuMA) protein. J. Cell Biol. 145, 29-43.

Mattern, K. A., Humbel, B. M., Muijsers, A. O., de Jong, L. and van Driel, R. (1996). hnRNP proteins and B23 are the major proteins of the internal nuclear matrix of HeLa S3 cells. J. Cell. Biochem. 62, 275-289.

McNally, J. G., Muller, W. G., Walker, D., Wolford, R. and Hager, G. L. (2000). The glucocorticoid receptor: rapid exchange with regulatory sites in living cells. Science 287, 1262-1265.

Mintz, P. J., Patterson, S. D., Neuwald, A. F., Spahr, C. S. and Spector, D. L. (1999). Purification and biochemical characterization of interchromatin granule clusters. EMBO J. 18, 4308-4320.

Miralles, F., Ofverstedt, L. G., Sabri, N., Aissouni, Y., Hellman, U., Skoglund, U. and Visa, N. (2000). Electron tomography reveals posttranscriptional binding of pre-mRNPs to specific fibers in the nucleoplasm. J. Cell Biol. 148, 271-282.

Mirkovitch, J., Mirault, M. E. and Laemmli, U. K. (1984). Organization of the higher-order chromatin loop: specific DNA attachment sites on nuclear scaffold. Cell 39, 223-232.

Mirkovitch, J., Spierer, P. and Laemmli, U. K. (1986). Genes and loops in 320, 000 base-pairs of the Drosophila melanogaster chromosome. J. Mol. Biol. 190, 255-258.

Misteli, T. and Spector, D. L. (1996). Serine/threonine phosphatase 1 modulates the subnuclear distribution of pre-mRNA splicing factors. Mol. Biol. Cell 7, 1559-1572.

Misteli, T., Caceres, J. F. and Spector, D. L. (1997). The dynamics of a premRNA splicing factor in living cells. Nature 387, 523-527.

Misteli, T. and Spector, D. L. (1998). The cellular organization of gene expression. Curr. Opin. Cell Biol. 10, 323-331.

Misteli, T. (2000). Cell biology of transcription and pre-mRNA splicing: nuclear architecture meets nuclear function. J. Cell Sci. 113, 1841-1849.

Monneron, A. and Bernhard, W. (1969). Fine structural organization of the interphase nucleus in some mammalian cells. J. Ultrastruct. Res. 27, 266288.

Nakayasu, H. and Ueda, K. (1985). Association of rapidly-labelled RNAs with actin in nuclear matrix from mouse L5178Y cells. Exp. Cell Res. 160, 319-330.

Nakayasu, H. and Berezney, R. (1989). Mapping replicational sites in the eucaryotic cell nucleus. J. Cell Biol. 108, 1-11.

Narayan, K. S., Steele, W. J., Smetana, K. and Busch, H. (1967). Ultrastructural aspects of the ribonucleo-protein network in nuclei of Walker tumor and rat liver. Exp. Cell Res. 46, 65-77.

Nelson, W. G., Pienta, K. J., Barrack, E. R. and Coffey, D. S. (1986). The role of the nuclear matrix in the organization and function of DNA. Annu. Rev. Biophys. Biophys. Chem. 15, 457-475.

Nickerson, J. A., Krochmalnic, G., Wan, K. M. and Penman, S. (1989). Chromatin architecture and nuclear RNA. Proc. Nat. Acad. Sci. USA 86, 177-181.

Nickerson, J. A., Blencowe, B. J. and Penman, S. (1995). The architectural organization of nuclear metabolism. Int. Rev. Cytol. 67-123.
Nickerson, J. A., Krockmalnic, G., Wan, K. M. and Penman, S. (1997). The nuclear matrix revealed by eluting chromatin from a cross-linked nucleus. Proc. Nat. Acad. Sci. USA 94, 4446-4450.

Nowak, G., Pestic-Dragovich, L., Hozak, P., Philimonenko, A., Simerly, C., Schatten, G. and de Lanerolle, P. (1997). Evidence for the presence of myosin I in the nucleus. J. Biol. Chem. 272, 17176-17181.

Oegema, K., Marshall, W. F., Sedat, J. W. and Alberts, B. M. (1997). Two proteins that cycle asynchronously between centrosomes and nuclear structures: Drosophila CP60 and CP190. J. Cell Sci. 110, 1573-1583.

Panning, B. and Jaenisch, R. (1998). RNA and the epigenetic regulation of $\mathrm{X}$ chromosome inactivation. Cell $\mathbf{9 3}, 305-308$.

Pardoll, D. M., Vogelstein, B. and Coffey, D. S. (1980). A fixed site of DNA replication in eucaryotic cells. Cell 19, 527-536.

Pederson, T. (2000). Half a century of 'the nuclear matrix'. Mol. Biol. Cell 11, 799-805.

Phair, R. D. and Misteli, T. (2000). High mobility of proteins in the mammalian cell nucleus. Nature 404, 604-609.

Politz, J. C., Browne, E. S., Wolf, D. E. and Pederson, T. (1998). Intranuclear diffusion and hybridization state of oligonucleotides measured by fluorescence correlation spectroscopy in living cells. Proc. Nat. Acad. Sci. USA 95, 6043-6048.

Politz, J. C., Tuft, R. A., Pederson, T. and Singer, R. H. (1999). Movement of nuclear poly(A) RNA throughout the interchromatin space in living cells. Curr. Biol. 9, 285-291.

Rando, O. J., Zhao, K. and Crabtree, G. R. (2000). Searching for a function for nuclear actin. Trends Cell Biol. 10, 92-97.

Razin, S. V., Gromova, II and Iarovaia, O. V. (1995). Specificity and functional significance of DNA interaction with the nuclear matrix: new approaches to clarify the old questions. Int. Rev. Cytol. 405-448.

Reyes, J. C., Muchardt, C. and Yaniv, M. (1997). Components of the human SWI/SNF complex are enriched in active chromatin and are associated with the nuclear matrix. J. Cell Biol. 137, 263-274.

Samarina, O. P., Lukanidin, E. M., Molnar, J. and Georgiev, G. P. (1968). Structural organization of nuclear complexes containing DNA-like RNA. $J$. Mol. Biol. 33, 251-263.

Schroder, H. C., Trolltsch, D., Wenger, R., Bachmann, M., Diehl-Seifert, B. and Muller, W. E. (1987). Cytochalasin B selectively releases ovalbumin mRNA precursors but not the mature ovalbumin mRNA from hen oviduct nuclear matrix. Eur. J. Biochem. 167, 239-245.

Shopland, L. S. and Lawrence, J. B. (2000). Seeking Common Ground in Nuclear Complexity. J. Cell Biol. 150, F1-F4.

Singh, O. P., Bjorkroth, B., Masich, S., Wieslander, L. and Daneholt, B. (1999). The intranuclear movement of Balbiani ring premessenger ribonucleoprotein particles. Exp. Cell Res. 251, 135-146.

Smetana, K., Steele, W. J. and Busch, H. (1963). A nuclear ribonucleoprotein network. Exp. Cell Res. 31, 198-201.

Smith, H. C., Puvion, E., Buchholtz, L. A. and Berezney, R. (1984). Spatial distribution of DNA loop attachment and replicational sites in the nuclear matrix. J. Cell Biol. 99, 1794-1802.

Smith, K. P., Moen, P. T., Wydner, K. L., Coleman, J. R. and Lawrence, J. B. (1999). Processing of endogenous pre-mRNAs in association with SC35 domains is gene specific. J. Cell Biol. 144, 617-629.

Spector, D. L. (1996). Nuclear organization and gene expression. Exp. Cell Res. 229, 189-197.

Stenoien, D. L., Mancini, M. G., Patel, K., Allegretto, E. A., Smith, C. L. and Mancini, M. A. (2000a). Subnuclear trafficking of estrogen receptoralpha and steroid receptor coactivator-1. Mol. Endocrinol. 14, 518-534.

Stenoien, D. L., Patel, K., Mancini, M. G., Dutertre, M., Smith, C. L., O'Malley, B. W. and Mancini, M. A. (2000b). FRAP reveals estrogen receptor-alpha mobility is ligand- and proteasome-dependent. Nature Cell Biol. (in press).

Sun, J. M., Chen, H. Y., Moniwa, M., Samuel, S. and Davie, J. R. (1999). Purification and characterization of chicken erythrocyte histone deacetylase 1. Biochemistry 38, 5939-5947.

Tan, J., Wooley, J. C. and LeStourgeon, W. M. (2000). Nuclear matrix-like filaments and fibrogranular complexes form through the rearrangement of specific nuclear ribonucleoproteins. Mol. Biol. Cell 11, 1547-1554.

Tubo, R. A. and Berezney, R. (1987). Nuclear matrix-bound DNA primase. Elucidation of an RNA priming system in nuclear matrix isolated from regenerating rat liver. J. Biol. Chem. 262, 6637-6642.

Tubo, R. A., Martelli, A. M. and Berezney, R. (1987). Enhanced processivity of nuclear matrix bound DNA polymerase alpha from regenerating rat liver. Biochemistry 26, 5710-5718. 
van Venrooij, W. J. and Janssen, D. B. (1978). HnRNP particles. Mol. Biol. Rep. 4, 3-8.

van Wijnen, A. J., Bidwell, J. P., Fey, E. G., Penman, S., Lian, J. B., Stein, J. L. and Stein, G. S. (1993). Nuclear matrix association of multiple sequence-specific DNA binding activities related to SP-1, ATF, CCAAT, C/EBP, OCT-1, and AP-1. Biochemistry 32, 8397-8402.

Vogelstein, B., Pardoll, D. M. and Coffey, D. S. (1980). Supercoiled loops and eucaryotic DNA replicaton. Cell 22, 79-85.

Walker, B. W., Lothstein, L., Baker, C. L. and LeStourgeon, W. M. (1980). The release of $40 \mathrm{~S}$ hnRNP particles by brief digestion of HeLa nuclei with micrococcal nuclease. Nucl. Acids Res. 8, 3639-3657.

Wan, K. M., Nickerson, J. A., Krockmalnic, G. and Penman, S. (1999). The nuclear matrix prepared by amine modification. Proc. Nat. Acad. Sci. USA 96, 933-938.

Wansink, D. G., Schul, W., van der Kraan, I., van Steensel, B., van Driel, R. and de Jong, L. (1993). Fluorescent labeling of nascent RNA reveals transcription by RNA polymerase II in domains scattered throughout the nucleus. J. Cell Biol. 122, 283-293.

Wansink, D. G., Sibon, O. C., Cremers, F. F., van Driel, R. and de Jong, L. (1996). Ultrastructural localization of active genes in nuclei of A431 cells. J. Cell. Biochem. 62, 10-18.
Wasser, M. and Chia, W. (2000). The EAST protein of drosophila controls an expandable nuclear endoskeleton [see comments]. Nature Cell Biol. 2, 268-275.

Wei, X., Somanathan, S., Samarabandu, J. and Berezney, R. (1999). Three-dimensional visualization of transcription sites and their association with splicing factor-rich nuclear speckles. J. Cell Biol. 146, 543-558.

Xing, Y. G. and Lawrence, J. B. (1991). Preservation of specific RNA distribution within the chromatin-depleted nuclear substructure demonstrated by in situ hybridization coupled with biochemical fractionation. J. Cell Biol. 112, 1055-1063.

Zeitlin, S., Parent, A., Silverstein, S. and Efstratiadis, A. (1987). Pre-mRNA splicing and the nuclear matrix. Mol. Cell Biol. 7, 111-120.

Zeitlin, S., Wilson, R. C. and Efstratiadis, A. (1989). Autonomous splicing and complementation of in vivo-assembled spliceosomes. J. Cell Biol. 108, 765-777.

Zeng, C., van Wijnen, A. J., Stein, J. L., Meyers, S., Sun, W., Shopland, L., Lawrence, J. B., Penman, S., Lian, J. B., Stein, G. S. et al. (1997). Identification of a nuclear matrix targeting signal in the leukemia and bonerelated AML/CBF-alpha transcription factors. Proc. Nat. Acad. Sci. USA 94, 6746-6751. 